\title{
Sexual Risk Behaviors among First Year College Students, 2000-2002
}

\author{
Diana Flannery and Lyndall Ellingson \\ California State University, Chico
}

\begin{abstract}
Objective: To determine sexual risk behaviors among first semester college freshman during a three year period. Method: A sexual activity questionnaire was used to collect data from 778 students enrolled in an Introduction to University Life course. Results: Seventy-one percent of the students had engaged in intercourse, had a mean age of 18.2, a mean number of lifetime partners was 3.5, a mean age of first intercourse was 16.4, and a mean number of partners in the past 3 months was 1.3. Students had very low rates of reported STIs and over 60 percent used a condom the last time they had sex. Fifteen percent of first year college women and $16 \%$ of men had engaged in anal intercourse. Women who engaged in anal intercourse had first intercourse at a younger age, had a greater number of partners in the last 3 months, were happier with their body, and masturbated more. Men who had engaged in anal intercourse had first intercourse at a younger age, had a greater number of lifetime partners, had a greater number of partners in the last 3 months, and were happier with their body. Conclusion: This study underscores the importance of expanding our understanding of sexual behaviors of first year college students and openly addressing anal intercourse as a part of the sexual repertoire of college men and women.
\end{abstract}

(C) 2003 Californian Journal of Health Promotion. All rights reserved.

Keywords: risk behavior, sexuality, college health, students

\section{Introduction}

The epidemiology of sexually transmitted diseases suggests a heightened risk for young adults, particularly college students. Approximately 3 million cases of sexually transmitted infections occur each year among young adults and HIV is the fifth leading cause of death among persons aged 25-44 years in the United States (CDC, 2000a; 2000b; MMWR, 1998). These data underscore the importance of understanding and addressing the sexual behaviors of the more than 14 million college students in the United States (U.S. Bureau of the Census, 2001).

Several risk factors are associated with increased risk of sexually transmitted infections (STIs): Earlier age at first intercourse, multiple sexual partners within the past year, history of STIs, and receptive anal intercourse. Each of these factors is more prevalent among young adults compared to younger or older cohorts (Institute of Medicine, 1997; European Study Group on Heterosexual Transmission of HIV, 1992). As a unique population of young adults, college students exhibit conflicting sexually transmitted infection (STI) risk behaviors compared to nonstudents. College students are more likely to have multiple sexual partners and use drugs and alcohol proximal to sexual activity, as well as less likely to exhibit safer sex communication and consistent condom use. Conversely, they are more likely to have higher levels of sexual selfefficacy and use a condom if a partner requests, both of which practices are associated with lower risk of HIV infection (Lewis \& Malow, 1997).

College freshmen are a special subset of the college student population, with the traditionalaged freshmen student poised between adolescence and young adulthood. A review of the literature found no recent studies on college freshmen sexual behaviors, with most studies dating from the early-to-mid 1990's - a significantly different era relative to HIV-related sexuality education and knowledge (DiIorio, Parsons, Adame, Carlone, 1993; Douglas, 
Warren, Kann, et al.,1996; Lewis \& Malow, 1997; McGuire, Shega, Nicholls, Deese, \& Landefeld, 1992; Reinisch \& Sanders, 1992; Reinisch, Hill, \& Sanders, 1995; Simkins, 1994). The most recent study found (Siegal, 1999) concluded that while sexual risk behaviors increased with years in college, freshmen behaviors were significant enough to warrant concern for sexual health. In a convenience survey of sexual risk behaviors among college students $(\mathrm{N}=797)$ and then analyzed by class, $54 \%$ freshmen females (FF) vs. 49\% freshmen males (FM) reported ever having had vaginal and/or oral intercourse, $37 \%$ FF vs. $28 \%$ FM reported being currently "sexually active, 24\% FF vs. $35 \%$ FM had had 3 or more lifetime partners, $6 \% \mathrm{FF}$ vs. 3\% FM had ever had anal intercourse, and $2 \%$ of all sexually experienced freshmen reported having contracted an STI.

Among sexual behaviors that increase the likelihood of exposure to an STI anal intercourse holds unique physical and social risks. Anal intercourse is associated hepatitis B infection, anorectal human papilloma virus, and cancer (Best, 2001). Anal intercourse is also associated with other sexual risk behaviors. In their study of heterosexual anal intercourse among college students, Baldwin and Baldwin (2000) reported anal intercourse to be associated with younger age at first vaginal intercourse, a history of at least one STI, and use of less effective contraceptive methods. Reinisch and Sanders (1992) found a significant positive correlation between anal intercourse and number of sexual partners $($ mean $=5.6$ and range $=1-100$; $\mathrm{p}<.011$ ). In their review of sexual behavior in the United States, Siedman and Rieder (1994) present several studies that found an inverse correlation between age of first intercourse and condom use and a positive relationship between STIs and anal intercourse. Moreover, most heterosexuals engaging in anal intercourse do not use a condom, and unprotected, receptive anal sex presents more of a risk of sexual HIV transmission for women than does unprotected vaginal intercourse (Erickson, Bastani \& Maxwell, 1995; Halperin, 1999).

The social risks of anal intercourse come from the silence created around this issue by cultural mores proscribing anal intercourse and the assumption that only gay men participate in this activity. This silence is found even among welldesigned sexuality education materials and in college human sexuality curricula and is shear negligence when faced with the fact that a significant portion of young adults (ranging from $17 \%$ (Reinisch, Hill, \& Sanders, 1995) to $25 \%$ (Baldwin \& Baldwin, 2000) to $32 \%$ (Flannery \& Ellingson, 2003)) - heterosexual and homosexual alike - participate in this activity.

This study reports on sexual risk behaviors and correlates in a three-year study among college freshmen and provides ideas on how to use this information to enhance college human sexuality courses to address the sexual repertoire of current college populations.

\section{Method}

The study sample included 778 students enrolled in an undergraduate, elective Introduction to University Life course at California State University, Chico (CSUC). Data collection began December $2000(n=261)$, was collected again a year later in December $2001(n=278)$, and again December $2002(\mathrm{n}=239)$. Data was collected in 16 sections each fall term and the average class size was approximately 23 students.

CSUC enrolls approximately 16,000 students who are predominantly young, white, and middle class. The Introduction to University Life course was designed primarily as a lower division, general education requirement. The course includes a range of declared and undeclared freshman.

Approximately two sessions of the course curriculum addressed sexual health. In this program, survey data were used to open discussion about the reality of the sexual lives of first year college students. At the beginning of a two day lecture on sexual health, students worked in small groups and were asked to predict student behavior patterns (see Appendix A). After allowing approximately 15 minutes for students to discuss and record their predictions, the instructor presented the actual 
data as the students recorded the factual information (see Power Point 1). Each topic, such as lifetime number of partners, sexual identity, alcohol and sexual behavior, anal and oral sex practices, and rape were discussed in terms of the health risks, responsibilities, and cultural messages of sexual health.

The 23-item Sexual Activity Questionnaire (see Appendix B) was developed both to personalize the sexual risks and responsibilities of this student population and to identify sexual behaviors and attitudes among college freshman enrolled in the course. To attain the highest level of anonymity in a classroom setting, completed surveys were placed in an envelope while students exited the classroom and measurement of demographic data was limited to gender and age. Moreover, no personally identifying information was collected such as racial/ethnic background.

The survey was distributed to students during the final 14th -15 th weeks of the semester. One instructor who rotated through the 2 session sexual health component of each section was responsible for the development and distribution of the survey. The survey was a paper-andpencil questionnaire consisting of 10 dichotomous, 10 multiple choice, and 3 openended questions. The survey was patterned after the 1999 Youth Risk Behavior Survey. Three health educators reviewed the questionnaire for content validity, readability, and comprehensiveness. Content included both sexual risk and sexual self-efficacy items.

This study was designed to determine behaviors sex positive and negative behaviors associated with anal intercourse. Independent samples ttests were used to compare "yes" versus "no" responses to "Have you ever engaged in anal intercourse?" to 3 dependent variables: (a) age at first intercourse; (b) number of lifetime partners; (c) number of partners in the last three months; (d) history of STIs; (e) frequency of masturbation; and (f) body image.

\section{Results}

In order to examine the sexual behavior of traditionally aged freshman, 19 students were excluded for being over age 19 leaving a total sample of 778 traditional age students (ages 1719) $(\mathrm{M}=18.2$ years). Of the sample, $71 \%$ $(n=549)$ reported that they were sexually experienced (SE) (defined as ever having engaged in vaginal-penile intercourse) (see PowerPoint 1). Ninety-nine percent selfidentified as heterosexual. In order to examine the sexual risk and prevention behaviors of college freshman, data was sorted by sexual experience as well as gender (see Table 1).

Descriptive statistics of the SE women show that mean age at first intercourse was 16.3, the mode was 17 years and median was 16.0 years. For men, the mean age at first intercourse was 16.4, the mode and median were 16.0 years. For females, the mean number of reported lifetime partners was 3.4 , the mode was 1 partner, and median was 2.0 partners. For males, the mean number of reported lifetime partners was 3.7, the mode was 1 partner, and median was 2.0 partners.

Only $1.1 \%$ of females and $1.2 \%$ males reported ever contracting genital warts, chlamydia, or genital herpes; $4.8 \%$ of females and $5.1 \%$ of males were not sure, with the majority (94\%) of subjects reported never knowingly having had an STI. Sixty percent of females and $64 \%$ of males used a condom the last time they had intercourse. Twenty four percent of females and $19 \%$ of males reported being screened for HIV infection. Other risk factors included $31 \%$ of females and $42 \%$ of males used alcohol or drugs the last time they had sex; $5 \%$ of females and $7 \%$ of males had been involved in a pregnancy; $39 \%$ of females and $51 \%$ of males had a one night stand. For SE students, twenty percent of females and $10 \%$ of males reported having had sex against their will. 
Table 1

The Sexual Risk and Prevention Practices of College Freshman 2000-2002

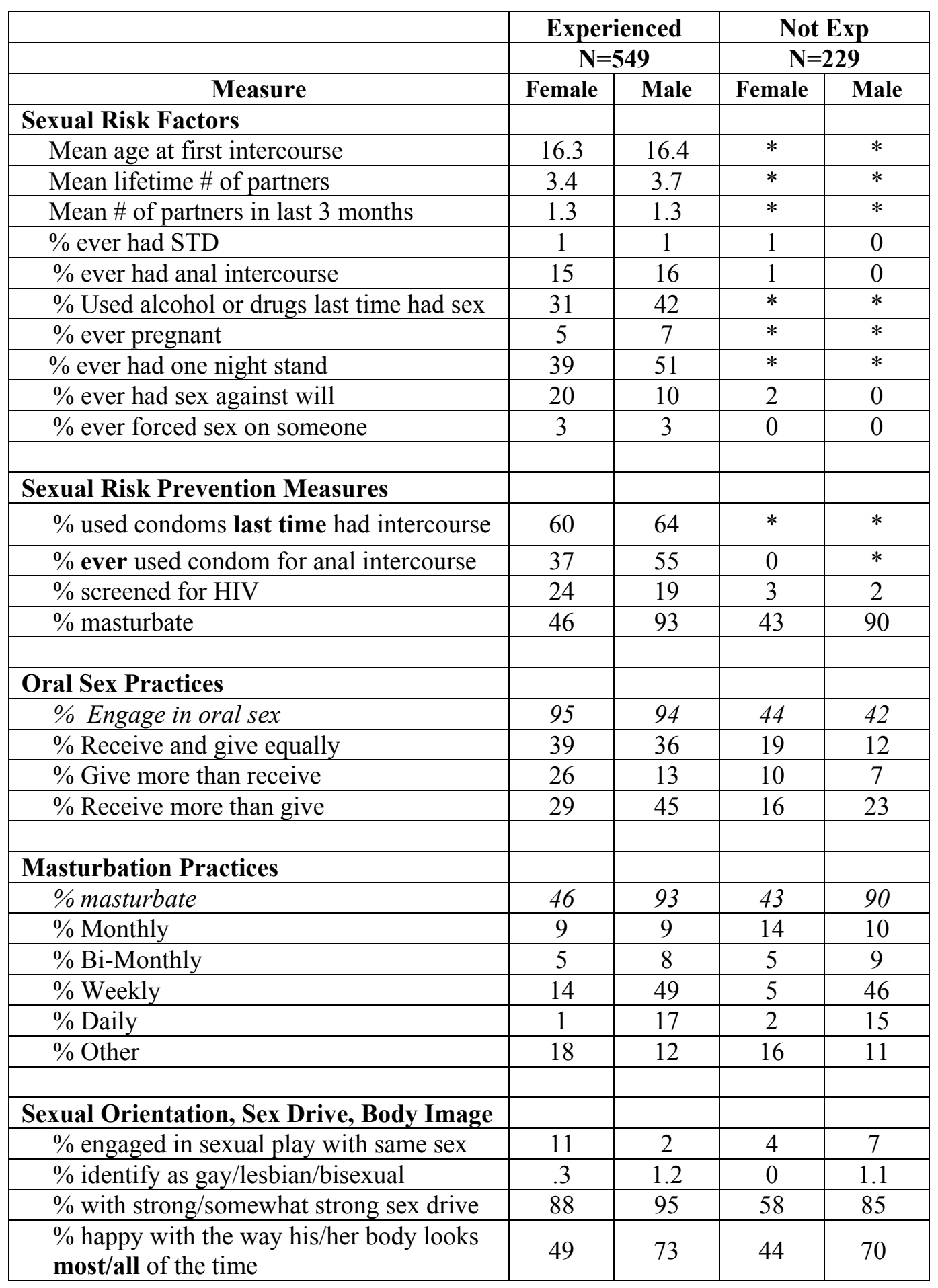


Descriptive statistics of the SE women show that mean age at first intercourse was 16.3, the mode was 17 years and median was 16.0 years. For SE men, the mean age at first intercourse was 16.4, the mode and median were 16.0 years. For females, the mean number of reported lifetime partners was 3.4 , the mode was 1 partner, and median was 2.0 partners. For males, the mean number of reported lifetime partners was 3.7 , the mode was 1 partner, and median was 2.0 partners.

Only $1.1 \%$ of females and $1.2 \%$ males reported ever contracting genital warts, chlamydia, or genital herpes; $4.8 \%$ of females and $5.1 \%$ of males were not sure, with the majority $(94 \%)$ of subjects reported never knowingly having had an STI. Sixty percent of females and $64 \%$ of males used a condom the last time they had intercourse. Twenty four percent of females and $19 \%$ of males reported being screened for HIV infection. Other risk factors included $31 \%$ of females and $42 \%$ of males used alcohol or drugs the last time they had sex; $5 \%$ of females and $7 \%$ of males had been involved in a pregnancy; $39 \%$ of females and $51 \%$ of males had a one night stand. For SE students, twenty percent of females and $10 \%$ of males reported having had sex against their will.
For non coital behaviors, $95 \%$ of SE females and $94 \%$ of SE males engaged in oral sex. Among sexually inexperienced (SI) $44 \%$ of females and $42 \%$ of males engaged in oral sex. For masturbation, $46 \%$ of SE females practiced masturbation and $93 \%$ of SE males did. For SI females $43 \%$ practiced masturbation and $90 \%$ of SI males did.

Fifteen percent of SE females and 16\% of SE males had engaged in anal intercourse. Of those who engaged anal intercourse, $63 \%$ of females and $45 \%$ of males reported never using a condom with anal intercourse. Tables 2 and 3 show the results from independent-sample t-tests used to compare yes versus no responses to "Have you ever engaged in anal intercourse?" for females and males. For females, a significant difference was found for age of first intercourse; those reporting "yes" for anal intercourse had a younger age at first intercourse $(\mathrm{M}=16.0$ years) than for those indicating "no" $(\mathrm{M}=16.5$ years). The number of partners in the last 3 months was significantly higher for those indicating anal intercourse $(M=1.6)$ than for those indicating no $(\mathrm{M}=1.2)$. Females who engaged in anal intercourse were happier with the way their body looked $(\mathrm{M}=2.4)$ than those indicating no $(\mathrm{M}=2.7)$ and masturbated more $(\mathrm{M}=1.7)$ than those indicating no $(\mathrm{M}=1.0)$.

Table 2

Independent-samples T-tests: Sexual Risk Behaviors and Anal Intercourse for Females

\begin{tabular}{|lr|c|c|c|c|}
\hline & & \multicolumn{2}{|c|}{ Anal Intercourse } & & \\
\hline & & Yes & No & Levene's F & p \\
\hline First age of intercourse & $\mathrm{N}$ & 44 & 251 & 2.59 & .021 \\
& Mean & 16.0 & 16.5 & & \\
& $\mathrm{SD}$ & 1.1 & 1.2 & & \\
\hline Number of partners last 3 months & $\mathrm{N}$ & 43 & 250 & 3.12 & .012 \\
& $\mathrm{~N}$ & 1.6 & 1.2 & & \\
& $\mathrm{SD}$ & 1.0 & .92 & & \\
\hline Happy with how body looks & $\mathrm{N}$ & 44 & 248 & 2.98 & .036 \\
& $\mathrm{Nean}$ & 2.4 & 2.7 & & \\
& $\mathrm{SD}$ & .72 & .89 & & \\
\hline Masturbation practices & $\mathrm{N}$ & 44 & & & \\
& $\mathrm{~N}$ & 250 & & \\
& $\mathrm{Mean}$ & 1.7 & 1.0 & & \\
$\mathrm{SD}$ & 1.8 & 1.4 & & \\
\hline
\end{tabular}


Table 3

Independent-samples T-tests: Sexual Risk Behaviors and Anal Intercourse for Males

\begin{tabular}{|c|c|c|c|c|}
\hline & $\begin{array}{r}A \\
\text { Inte }\end{array}$ & urse & & \\
\hline & Yes & No & Levene's F & p \\
\hline Age of first intercourse & $\begin{array}{c}41 \\
15.9 \\
1.7\end{array}$ & $\begin{array}{c}217 \\
16.6 \\
1.1\end{array}$ & 5.7 & .027 \\
\hline Number of lifetime partners & $\begin{array}{l}41 \\
6.5 \\
9.5\end{array}$ & $\begin{array}{l}218 \\
3.3 \\
3.7\end{array}$ & 25.0 & .043 \\
\hline $\begin{array}{r}\text { Number of partners last three months } \\
\mathrm{N} \\
\text { Mean } \\
\mathrm{SD}\end{array}$ & $\begin{array}{l}38 \\
1.9 \\
1.5\end{array}$ & $\begin{array}{r}217 \\
1.2 \\
1.1\end{array}$ & 8.9 & .004 \\
\hline Happy with how body looks & $\begin{array}{c}41 \\
1.9 \\
.81\end{array}$ & $\begin{array}{l}216 \\
2.2 \\
.84\end{array}$ & .11 & .043 \\
\hline
\end{tabular}

For males, a significant difference was found for age of first intercourse; those reporting "yes" for anal intercourse had a younger age at first intercourse $(\mathrm{M}=15.9$ years $)$ than for those indicating "no" $(\mathrm{M}=16.6$ years $)$. The number of lifetime partners was significantly higher for those indicating anal intercourse $(\mathrm{M}=6.5)$ than for those indicating no $(\mathrm{M}=3.3)$. The number of partners in the last 3 months was significantly higher for those indicating anal intercourse $(\mathrm{M}=$ 1.9) than for those indicating no $(M=1.2)$. Males who engaged in anal intercourse were happier with the way their body looked $(\mathrm{M}=1.9)$ than those indicating no $(\mathrm{M}=2.2)$.

\section{Discussion}

The sexual behaviors of first year college students in this investigation are consistent or elevated as compared to other studies. Both the mode of one lifetime sexual partners and the mean of 16 years at age at first intercourse are similar to ranges found in the studies reviewed (Reinisch \& Sanders, 1992; Reinisch, Hill, \& Sanders, 1995). Equally consistent with previous studies were the significant relationships found between anal intercourse and number of sexual partners and age at first intercourse (Reinisch \& Sanders, 1992; Baldwin \& Baldwin, 2000; Seidman \& Rieder, 1994).

In striking contrast to the similarities in sexual risk factors discussed above, the percentage of subjects in this study having ever engaged in anal intercourse $(15 \%$ and $16 \%$, females and males respectively) was higher than the most pertinent comparison study which found only $6 \%$ and $3 \%$ of college freshmen, females and males respectively, had had anal intercourse (Siegal, 1999). Of course sampling bias may have contributed to this elevated measure, with the possibility that freshmen enrolled in an elective University Life course are somehow qualitatively different than the (also) convenience sample of Siegal's. However, it is also likely that the sex-positive STI presentation in the Introduction to University Life course prior to data collection may have produced a more valid reporting of anal intercourse because of reduced social stigma about this sexual behavior. 
While the positive relationships between anal intercourse and other sexual risk behavior are well established, a secondary analysis of the data provides an interesting lens through which to consider the context in which anal intercourse occurs among young adults. Significant associations were found between 1) having had anal intercourse and body image, and 2) anal intercourse and frequency of masturbation. Using a reverse Likert scale to respond to the question "Are you happy with how your body looks?" ( $1=$ "all of the time" vs. $5=$ "never") freshmen men who had had anal intercourse were more likely to respond positively to the statement $(\mathrm{M}=2)$ than those who had not had anal intercourse $(M=2.2)$. Similarly, freshmen women who had had anal intercourse were more likely to feel positively about their bodies $(M=2.4)$ than were women who reported never having had anal intercourse $(M=2.7)$. Frequency of masturbation was positively associated with anal intercourse among freshmen women. In response to a Likert scale response set for the question "What best describes your masturbation practices?" (1="I never masturbate" vs. 6="I masturbate daily") women who had had anal intercourse were had a greater frequency of masturbation $(\mathrm{M}=1.7)$ vs. women who had not had anal intercourse $(\mathrm{M}=1.0)$. No studies reviewed reported similar variables or statistical tests, so comparison is not possible, but these results may suggest that anal intercourse is one of many behaviors practiced by individuals who are generally more 'sex-positive' or erotophilic: actively engaged in self-stimulation (vs. dyadic settings only), have positive feelings about their bodies, and are more sexually adventurous.

These data underscore the importance of expanding our understanding of sexual behaviors of college freshmen and openly addressing anal intercourse as a part of their sexual repertoire. The risks of vaginal intercourse are addressed more often than the risks of anal intercourse among heterosexuals. This may give men and women the false impression that anal intercourse is not as dangerous. In order to effectively address the topic of anal intercourse, health educators must move beyond their own cultural and personal inhibitions in dealing with stigmatized behaviors and give anal intercourse greater emphasis in HIV/STI prevention. Moreover, helping students understand the importance of minimizing their number of lifetime partners, becoming consistent condom users, reducing alcohol consumption, improving body image of women, understanding the risks of oral sex, and knowing where to access HIV and STI screening are also of importance.

Limitations of the study include convenience sampling and underestimation of stigmatized sexual behavior due to self-report. It is possible that students taking a University Life class are somehow significantly different in sexual behaviors from the general college freshmen population. The fact that an elevated frequency of anal intercourse was found in this study may indicate that the typical underreporting of stigmatized behavior was countered by the datacollection context. Data was collected after a frank, sex-positive STI presentation, which sought to create a safe environment for sharing sexual experiences and attitudes. We doubt that given the stigmatized status of anal intercourse, subjects falsely over reported this behavior. It is more likely that this environment allowed for more accurate reporting of this behavior. In order to better understand the sexual practices of college freshmen, future studies should employ probability sampling in similar sex-positive contexts to counterbalance the impact of selection bias and reduced social stigma on the data.

\section{Conclusion}

Moving beyond own cultural and personal inhibitions in dealing with stigmatized behaviors and honestly addressing the sexual health concerns of colleges students mirrors Surgeon General Satcher's Call to Action to Promote Sexual Health and Responsible Sexual Behavior (2001). In his report, the Surgeon General warns that "social inhibition impedes the development and implementation of effective sexual health and HIV/STD education programs, perpetuates misperceptions about individual risk and ignorance about the consequences of sexual activities and may encourage high-risk sexual practices." Satcher emphasizes opening communication and breaking the "code of 
silence" to encourage healthy behaviors. Satcher recognizes that the process of finding approaches to these solutions might be complex, but there is evidence of success. Satcher's Call to Action offers a guide to contextualize the goals of sexuality education today.

\section{References}

Baldwin J. A., \& Baldwin, J. D. (2000). Heterosexual anal intercourse: an understudied high-risk sexual behavior. Archives of Sexual Behavior, 29, 367-373.

Best, K. (2001). Anal intercourse presents serious HIV/STI risks. Network, 20(4), 29.

Centers for Disease Control and Prevention. (2000a). 1998 national vital statistics report. Atlanta, GA: Author.

Centers for Disease Control and Prevention. (2000b). Tracking the hidden epidemic: Trends in the STD epidemics in the US. Retrieved August 6, 2003, from http://www.cdc.gov/nchstp/dstd/ Stats Trends/Trends2000.pdf

Dilorio, C., Parsons, M. Adame, D., \& Carlone, J. (1993). Factors associated with use of safer sex practices among college freshmen. Research in Nursing and Health, 16, 343-50.

Douglas, K., Warren, C. W., Kann, L et al. (July 7-12, 1996). HIV infection and U.S. college students: How great is the risk? International Conference on AIDS. Abstract no. Tu.C.2667. Retrieved August 6, 2003, from http://gateway.nlm.nih.gov

Erickson, P .I., Bastani, R., Maxwell, A.. E., et al. (1995). Prevalence of anal sex among heterosexual in California and its relationship to other AIDS risk factors. AIDS Educational Preview, 7(60), $477-$ 493.

European Study Group on Heterosexual Transmission of HIV. (1992). Comparison of female to male and male to female transmission of HIV in 563 couples. British Medical Journal, 304, 809-813.

Flannery, D., Ellingson, L., Votaw, K. S., \& Schaefer, E. A. (2003). Anal intercourse and sexual risk factors among college women, 1993-2000. American Journal of Health Behavior, 27(3), 228-234.

Halperin, D. T. (1999). Heterosexual anal intercourse: prevalence, cultural factors, and HIV infection and other health risks, part I. AIDS Patient Care STDs, 13(12), 717-730.

Institute of Medicine. (1997). The hidden epidemic: Confronting sexually transmitted diseases. Washington, DC: National Academy Press.

Latman, N.S., \& Latman, A. I. (1995). Behavioral risk of human immunodeficiency virus/acquired immunodeficiency syndrome in the university student community. Sexually Transmitted Diseases, 22(2), 104-109.

Lewis J. E., \& Malow, R. M. (1997). HIV/AIDS risks in heterosexual college students. Journal of American College Health, 45(4), 147-159.

McGuire, E. III, Shega, J., Nicholls, G., Deese, P., Landefeld, C. S. (1992). Sexual behavior, knowledge, and attitudes about AIDS among college freshmen. American Journal of Preventive Medicine, 8, 226-233.

Morbidity and Mortality Weekly Report. (1998). Summary of Notifiable Diseases, 47(53), 1-93.

Reinisch, J. M., Hill, C. A., Sanders, S. A. et al. (1995). High-risk sexual behavior among heterosexual undergraduates at a midwestern university: A confirmatory study. Family Planning Perspectives, 27(2), 79-82.

Reinisch J. M., \& Sanders S. A. (1992). High-risk sexual behavior among heterosexual undergraduates at a midwestern university. Family Planning Perspectives, 24(3), 116-123.

Reports of the Surgeon General. (2001). Call to action to promote sexual health and responsible sexual behavior. U.S. Public Health Service. Retrieved August 6, 2003, from http://www.surgeongeneral.gov/library/sexualhealth/call.htm

Seidman, S. N., \& Rieder, R. O. (1994). A review of sexual behavior in the United States. American Journal of Psychiatry,151, 330-341.

Siegal, D. M., Klein, D. I., \& Roghmann, K. J. (1999). Sexual behavior, contraception, and risk among college students. Journal of Adolescent Health, 25, 336-343. 
Simkins, L. (1994). Risk of HIV transmission in sexual behaviors of college students. Psychological Reports, 74, 787-799.

U.S. Bureau of the Census. (2001). School Enrollment: 1965-2000. Table 239. Statistical Abstract of the United States. Retrieved August 6, 2003, from http://www.census.gov/prod/2001pubs/statab/sec04.pdf

\author{
Author Information \\ Diana Flannery, $\mathrm{PhD}^{*}$ \\ Associate Professor \\ Department of Health and Community Services \\ California State University, Chico \\ Chico, CA 95929-0505 \\ Ph. 530-898-4993 \\ Fax. 530-898-5107 \\ E-Mail: dflannery@csuchico.edu \\ Lyndall Ellingson, $\mathrm{PhD}$ \\ Associate Professor \\ Department of Health and Community Services \\ California State University, Chico \\ Chico, CA 95929-0505 \\ Ph. 530-898-6310 \\ E-Mail: lellingson@csuchico.edu \\ * Corresponding author
}




\section{Appendix A Sexual Activity Survey}

During the last three years (00-02), 778 first year college students enrolled in UNIV 001 at CSU, Chico were surveyed regarding their sexual behaviors. What percent of the students do you think were sexually active ?

Discuss with your group the following sexual practices and complete the following table with your best estimate of the behaviors of college freshman at CSU, Chico.

Gender Differences in Sexual Behaviors of Sexually Active First Semester Freshman Best Guess Actual Data

\begin{tabular}{|c|c|c|c|c|}
\hline \multirow{2}{*}{\multicolumn{5}{|c|}{ Sexual Risk Factors }} \\
\hline & & & & \\
\hline Mean age at first intercourse & & & & \\
\hline Mean lifetime \# of partners & & & & \\
\hline Mean \# of partners in last 3 months & & & & \\
\hline$\%$ ever had STD & & & & \\
\hline$\%$ ever had anal intercourse & & & & \\
\hline$\%$ Used alcohol or drugs last time had sex & & & & \\
\hline$\%$ ever pregnant & & & & \\
\hline$\%$ ever had one night stand & & & & \\
\hline$\%$ ever had sex against will & & & & \\
\hline$\%$ ever forced sex on someone & & & & \\
\hline Sexual Risk Prevention Measures & & & & \\
\hline$\%$ used condoms last time had intercourse & & & & \\
\hline$\%$ ever used condom for anal intercourse & & & & \\
\hline$\%$ screened for HIV & & & & \\
\hline$\%$ masturbate & & & & \\
\hline$\%$ used the birth control pill & & & & \\
\hline Oral Sex Practices & & & & \\
\hline$\%$ Engage in oral sex & & & & \\
\hline$\%$ Receive and give equally & & & & \\
\hline$\%$ Give more than receive & & & & \\
\hline$\%$ Receive more than give & & & & \\
\hline Masturbation Practices & & & & \\
\hline$\%$ masturbate & & & & \\
\hline$\%$ Monthly & & & & \\
\hline \% Bi-Monthly & & & & \\
\hline$\%$ Weekly & & & & \\
\hline \% Daily & & & & \\
\hline$\%$ Other & & & & \\
\hline Sexual Orientation, Sex Drive, and Body Image & & & & \\
\hline$\%$ engaged in sexual play with same sex & & & & \\
\hline$\%$ identify as gay/lesbian/bisexual & & & & \\
\hline$\%$ with strong/somewhat strong sex drive & & & & \\
\hline $\begin{array}{l}\% \text { happy with the way his/her body looks most/all of } \\
\text { the time }\end{array}$ & & & & \\
\hline
\end{tabular}

List 3 ways to reduce health risks associated with sexual intercourse/outercourse. 


\section{Appendix B \\ SEXUAL ACTIVITY SURVEY}

PLEASE DO NOT PUT YOUR NAME ON THE QUESTIONNAIRE. Your honesty in responding to the statements is very important. Be sure to answer every question, even if it does not apply.

1. What is your sex?

A. Female

B. Male

2. What is your age?

3. Have you ever had sexual intercourse?

A. Yes

B. No

4. How old were you when you had sexual intercourse for the first time?

A. I have never had sexual intercourse

B. years of age

5. During your life, with how many people have you had sexual intercourse?

A. I have never had sexual intercourse

B. number of partners

6. During the past 3 months, with how many people did you have sexual intercourse?

A. I have never had sexual intercourse

B. I have had sexual intercourse, but not during the past 3 months

C. 1 person

D. 2 people

E. 3 people

F. 4 people

G. 5 people

H. 6 or more people

7. Did you drink alcohol or use drugs before you had sexual intercourse the last time?

A. I have never had sexual intercourse

B. Yes

C. No

8. The last time you had sexual intercourse did you or your partner use a condom?

A. I have never had sexual intercourse

B. Yes

C. No

9. The last time you had sexual intercourse, what one method did you or your partner use to prevent pregnancy? (Select only one response.)

A. I have never had sexual intercourse

B. No method was used to prevent pregnancy

C. Birth control pills

D. Condoms

E. Depo-Provera (injectable birth control)

F. Withdrawal

G. Some other method

H. Not sure

10. How many times have you been pregnant or gotten someone pregnant?
A. 0 times
B. 1 time
C. 2 or more times
D. Not sure

11. Regarding your sexual orientation, you are primarily?

A. Heterosexual

B. Gay/lesbian

C. Bisexual

D. Don't know 
12. Have you ever engaged in sexual play with someone of the same sex?
A. Yes
B. No

13. Which of the following best describes your masturbation practices?
A. I never masturbate
B. Other (this is some amount between never and monthly)
C. Monthly
E. Bi-monthly
F. Weekly
G. Daily

14. Which of the following best describes your oral-genital sexual play?
A. Does not apply
B. Received and given equally
C. I usually give more than I receive
D. I usually receive more than I give

15. Have you ever had sexual intercourse on a "one night stand?"
A. Yes
B. No

16. Have you ever engaged in anal intercourse?
A. Yes
B. No

17. If you answered yes to anal intercourse was a condom used?

A. I have never engaged in anal intercourse

B. Always

A. Sometimes

B. Never

18. Have you ever contracted genital warts, chlamydia, or genital herpes?
A. Yes
B. No
C. Not sure

19. Have you ever been tested for HIV disease?
A. Yes
B. No

20. How would you describe your sex drive?
A. Very strong
B. Somewhat strong
C. Not very strong
D. No sex drive

21. Are you happy with the way your body looks?
A. All of the time
B. Most of the time
C. Sometimes
D. Rarely
E. Never

22. Have you ever experienced forced sexual intercourse?
A. Yes
B. No

23. Have you ever forced someone to engage in sexual intercourse with you?
A. Yes
B. No 